\title{
SuperPath approach is a recommendable option in frail patients with femoral neck fractures: a case-control study
}

\author{
Antonio Benedetto Cecere ${ }^{1}\left[\right.$ ] Annalisa De Cicco $^{1}\left([) \cdot\right.$ Gaetano Bruno $^{2} \cdot$ Giuseppe Toro $^{1}\left(\mathbb{D} \cdot\right.$ Giacomo Errico $^{2}$. \\ Adriano Braile $^{1}$ (1) Alfredo Schiavone Panni ${ }^{1}$ (1)
}

Received: 22 June 2021 / Accepted: 31 August 2021 / Published online: 4 September 2021

(c) The Author(s) 2021

\begin{abstract}
Introduction The treatment of intracapsular femoral neck fractures (FNFs) in the elderly is usually based on hip replacement, both total hip arthroplasty (THA) and hemiarthroplasty (HA). Recently, several tissue-sparing approaches for hip arthroplasty had been described with promising results in terms of hospitalization length, blood loss and dislocation rate. The aim of the present study was to compare the blood loss and the transfusion rate in a cohort of patients with FNF treated using an HA through both the SuperPath (SP) and the traditional posterolateral (PL) approaches.

Materials and methods We retrospectively collected data from patients affected by FNFs between January 2018 and February 2020. All patients with intracapsular FNF treated with a single HA implant (Profemur L, MicroPort Orthopedics Inc., USA) via PL or SP approaches were included. Exclusion criteria were pathological fractures, polytrauma and preoperatively transfused patients.

Results Thirty-five patients were included and analysed in the present study. 17 patients were classified in the SP group, and 18 in the PL one. The rate of antithrombotic therapy was higher in the SP group compared with the PL group [10 (58, $82 \%)$ vs $4(22,2 \%)$ ]. While the two groups did not differ in terms of preoperative haemoglobin $(\mathrm{Hb}), 48 \mathrm{~h}$ postoperative $\mathrm{Hb}$ and $\mathrm{Hb}$ reduction, a significative difference was observed in terms of blood transfusion rate (1 SP vs 9 PL, $p=0.0072$ ). Conclusions The SuperPath approach in patients with FNF under antithrombotic therapy assures lower transfusion rate, potentially reducing complication rates and improving patients' outcomes.
\end{abstract}

Keywords Hip fracture $\cdot$ Blood loss $\cdot$ Blood transfusion $\cdot$ Surgical approach $\cdot$ SuperPath $\cdot$ Hemiarthroplasty

\section{Introduction}

The treatment of intracapsular femoral neck fractures (FNFs) in the elderly is usually based on hip replacement, both total hip arthroplasty (THA) and hemiarthroplasty (HA). The choice between these two techniques is still debated. HA is generally preferred in older patients, because of lower surgical time, blood loss and dislocation rate [1-3]. Moreover, the risk of early revision due to acetabular wear related to HA

Giuseppe Toro

giusep.toro@gmail.com

1 Department of Medical and Surgical Specialties and Dentistry, University of Campania "Luigi Vanvitelli", Via L. De Crecchio 4, 80138 Naples, Italy

2 Unit of Orthopaedics and Traumatology, AORN Sant'Anna E San Sebastiano, Caserta, Italy could be considered irrelevant in the very elderly, considering their low functional demand [4].

Recently, several tissue-sparing approaches for hip arthroplasty have been described with promising results in terms of hospitalization length, blood loss and dislocation rate [5-7]. The SuperPath (SP) approach is a posterior tissuesparing hip approach, already successfully used to treat FNFs in the elderly [8]. Also in this population early mobilization, preserved gait kinematics and pain reduction could be achievable using tissue-sparing approaches [8].

Moreover, compared to the traditional posterolateral (PL) approach, the SP, preserving short external rotator tendons and the posterior capsule, further reduces the blood loss and the risk of hip dislocation. In frail patients, even a slight reduction of haemoglobin might be life threatening, and therefore a high blood transfusion rate was reported in patients with FNF [9]. However, blood transfusions are not risk free and significantly impact the healthcare system 
in terms of both direct and indirect costs. In fact, a higher risk of early morbidity and mortality among patients with geriatric hip fracture was observed [9]. Some specific complications were reported with blood transfusions, including transfusion-related lung injury (TRALI) and multi-organ dysfunction, due to a decrease in the red cell ability of oxygen delivery [10-12]. Additionally, although in the last few years the risk of infection transmission and lethal transfusion reactions had been constantly decreased, the incidence of any type of transfusion reaction is still consistent. In fact, Castillo et al. estimated an incidence of transfusion-related reactions in up to $1 \%$ of patients [12].

The aim of the present study was to compare the blood loss and the transfusion rate in a cohort of patients with FNF treated using an HA through both the SP and the traditional PL approaches.

Our hypothesis was that the use of the SP approach would be able to reduce blood loss and blood transfusion rate in a population of elderly with fragility FNF.

\section{Materials and methods}

We retrospectively collected data from patients affected by FNFs between January 2018 and February 2020. All patients with intracapsular FNF treated with a single HA implant (Profemur L, MicroPort Orthopedics Inc, USA) via PL or SP approaches were included. Exclusion criteria were pathological fractures, polytrauma and preoperatively transfused patients.

We collected demographic data, length of hospitalization, comorbidities, length of surgical procedure, transfusion rate, and haemoglobin (HB) values preoperatively and $48 \mathrm{~h}$ after surgery. The amount of blood loss was evaluated through Delta HB values, defined as the difference between preoperative and $48 \mathrm{~h}$ postoperative haemoglobin values.

Depending on the surgical approach used, patients were divided into two groups: SuperPath (SP) and posterolateral (PL) group. In all cases the prosthesis was implanted in the lateral decubitus over the unaffected side. In the SP approach, the affected hip was positioned at $45^{\circ}$ of flexion and $10-15^{\circ}$ of internal rotation. A 6-8 $\mathrm{cm}$ skin incision was performed taking the greater trochanter as a reference. After opening the gluteal fascia, the gluteus maximus was separated and the space between the gluteus minimus and the piriformis was exposed to access the capsule. The joint tendons or external rotator muscles were not excised. In the PL group, the skin incision begins posterior to the lateral side of the greater trochanter and runs distally about $6 \mathrm{~cm}$ along the femoral axis. Proximally, the incision runs slightly curved towards the PSIS to a point approximately $6 \mathrm{~cm}$ proximal to the greater trochanter. The fibres of the gluteus maximus were dissected and the greater trochanter was visible. The external rotators were released and retracted medially, and the capsule was exposed.

To identify differences between groups, descriptive statistics, Student's $T$ test and Fisher exact tests were used. Significance was set at $p<0.05$.

All patients provided written and informed consent allowing to undergo surgery and to have their data collected for scientific and audit purposes, as a standard protocol. The present study has been performed in accordance with the ethical standards as laid down in the 1964 Declaration of Helsinki and its later amendments or comparable ethical standards. According to Italian law, formal ethics approval was not required for this study, as it involved routine tests and patient evaluations.

\section{Results}

During the inclusion period, 613 patients with an FNF were admitted to our institution, 186 of them were affected by an intracapsular one. Forty-seven intracapsular fractures were treated with HA. Among these, 38 Profemur L stems were implanted. Three of 38 patients were excluded, 1 because of pathological fracture and 2 because of receiving a blood transfusion prior to surgery. Therefore, 35 were included and analysed in the present study. 17 patients were classified in the SP group, whereas 18 in the PL one (see Fig. 1).

Patients' data and group distribution are shown in Table 1.

The two groups did not differ in age (mean $84 \mathrm{SP}$ vs 85.1 $\mathrm{PL}$ ), sex distribution (M:F ratio: 1:4.6 SP vs 1:5 PL), length of surgery (minutes: $82.2 \mathrm{SP}$ vs 81.39 in PL) and length of hospitalization (days: 12.65 SP vs $13.83 \mathrm{PL}$ ).

Comorbidities were more commonly represented by chronic hypertensive cardiomyopathy (HC), chronic atrial fibrillation (CAFib), chronic heart failure (CHF) and type 2 diabetes mellitus (DM type 2) in both groups. The rate of antithrombotic therapy was higher in the SP group compared with the PL group $[10(58,82 \%)$ vs $4(22,2 \%), p$ value 0.0799].

Haemoglobin values are shown in Table 2. The groups did not differ in terms of preoperative $\mathrm{Hb}(12.33 \mathrm{mg} / \mathrm{dL}$ SP VS $12.29 \mathrm{mg} / \mathrm{dL} \mathrm{PL}), 48 \mathrm{~h}$ postoperative $(10,04 \mathrm{mg} / \mathrm{dL} \mathrm{SP}$ VS $9.81 \mathrm{mg} / \mathrm{dL}$ PL) and DELTA Hb $(2.29 \mathrm{mg} / \mathrm{dL}$ SP VS $2.48 \mathrm{mg} / \mathrm{dL}$ ) values.

The two groups significantly differed in terms of blood transfusion rate (1 SP vs $9 \mathrm{PL}, p=0.0072$ ).

\section{Discussion}

FNFs are considered as one of the most relevant health problems that the Western civilization has to face, considering the constant increase in terms of incidence, costs [13, 14] 


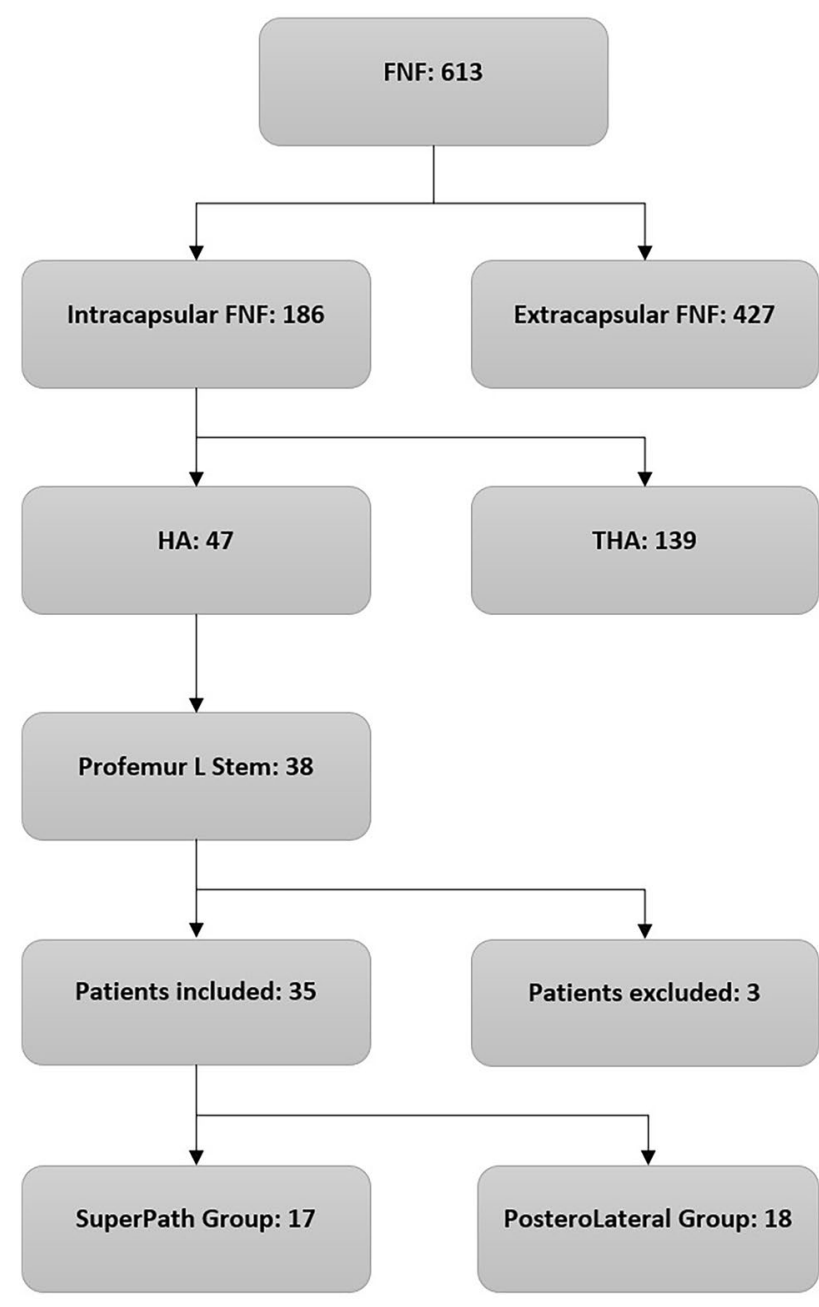

Fig. 1 Patients' selection process and a 1-year mortality rate of up to $33 \%$ [15]. FNFs are generally classified in extracapsular and intracapsular. These two types of fractures widely differ in terms of management, and patients' characteristics and outcomes [16]. Intracapsular FNFs in the elderly are generally treated using both THA and HA. These latter are associated with lower surgical time and dislocation rate [17], representing thus a viable option especially in the very elderly.

THA in this population are associated with a high risk of life-threatening complications including dislocations, thromboembolism, infections and periprosthetic fractures (PPF) [16, 18-20]. One of the most relevant factors that could influence the outcomes of the THA in the elderly with FNF is the poor bone quality [21]. The surgical approach could influence the frequency of some complications. In example, it was observed that both the lateral and the anterolateral approaches were associated with a lower dislocation rate compared to the PL [3]. Minimally invasive approaches present the supposed benefits of minimizing damage to surrounding soft tissues, with lower dislocation rates, reduced pain, early mobilization and lower hospitalization [22].

However, FNF bad outcomes are more frequent in nursing home patients with multiple comorbidities. For this reason, the use of tissue-sparing techniques would be useful in this population to improve rehabilitation and prevent complications. Pulmonary infections, deep vein thrombosis, muscular dystrophy and pressure ulcers are the main comorbidities related to long-term immobilization and postoperative pain [23].

The present study represents one of the few reports that analysed the reliability of the SP approach for the treatment of FNF in the elderly [8, 24, 25].

Our findings were similar to those reported by $\mathrm{Xu}$ et al. [24], which did not find a difference in total blood loss
Table 1 Characteristics of the study groups

\begin{tabular}{llll}
\hline & SP group & PL group & $p$ value \\
\hline Total number & 17 & 18 & n.a \\
Sex & $3 \mathrm{~m}, 14 \mathrm{f}$ & $3 \mathrm{~m}, 15 \mathrm{f}$ & 1 \\
Age (SD) & $84 y(\sigma 7,45)$ & $85,1 y(\sigma 7,72)$ & 0.667 \\
Length of hospitalization days (SD) & $12,65(\sigma 4,65)$ & $13,83(\sigma 3,71)$ & 0.206 \\
Chronic atrial fibrillation (\%) & $5(29,4 \%)$ & $2(11,1 \%)$ & 0.2285 \\
Hypertensive cardiomyopathy (\%) & $5(29,4 \%)$ & $6(33 \%)$ & 1 \\
Chronic heart failure (\%) & $3(17,6 \%)$ & $1(5,55 \%)$ & 0.3377 \\
DM type 2 (\%) & $2(11,7 \%)$ & $1(5,55 \%)$ & 0.6026 \\
Senile dementia (\%) & $1(5,9 \%)$ & $2(11,1 \%)$ & 1 \\
Epilepsy (\%) & $1(5,9 \%)$ & $0(0 \%)$ & 0.4857 \\
No comorbidity (\%) & $3(17,6 \%)$ & $6(33 \%)$ & 0.4430 \\
Antithrombotic therapy (\%) & $10(58,82 \%)$ & $4(22,2 \%)$ & 0.0799 \\
Surgical time min (SD) & $82,2(\sigma 37,42)$ & $81,39(\sigma 48,71)$ & 0.458 \\
Transfusions (\%) & $1(5,88 \%)$ & $9(50 \%)$ & 0.0072 \\
\hline
\end{tabular}

$S P$ SuperPath, $P L$ posterolateral 
Table 2 Haemoglobin value distribution in the studied groups

\begin{tabular}{llll}
\hline HB values $(\mathrm{mg} / \mathrm{dl})$ & SP group $($ mean, SD) & PL group (mean, SD) & $p$ value \\
\hline Preoperative HB & $12,33(\sigma 1,31)$ & $12,29(\sigma 1,69)$ & $0,936,984,825$ \\
48 h postoperative Hb & $10,04(\sigma 1,06)$ & $9,81(\sigma 1,94)$ & $0,664,722,034$ \\
Hb Delta & $2,29(\sigma 1,01)$ & $2,48(\sigma 1,41)$ & $0,640,803,887$ \\
\hline
\end{tabular}

$S P$ SuperPath, $P L$ posterolateral, $H B$ haemoglobin

\begin{tabular}{llll}
\hline Transfusion rate & SP group & PL group & $p$ value \\
\hline Jianbo 2019 [8] & $4.0 \%(2 / 50)$ & $18 \%(9 / 50)$ & 0.025 \\
Xu 2019 [24] & $26.9 \%(14 / 52)$ & $35.9 \%(28 / 78)$ & \\
Present study & $5.88 \%(1 / 17)$ & $50 \%(9 / 18)$ & 0.0072 \\
\hline Hb delta values & SP group & PL group & $p$ value \\
\hline Xu 2019 [24] (72 h postop) & $2.67 \pm 1.79$ & $2.48 \pm 1.51$ & \\
Present study (48 h postop) & $2.29( \pm 1.01)$ & $2.48( \pm 1.41)$ & 0.664722034 \\
\hline
\end{tabular}

SP SuperPath, $P L$ posterolateral, $H B$ haemoglobin
Table 3 Comparison between the present study and the available literature in transfusion rate and $\mathrm{HB}$ reduction
In fact, lowering the transfusion rate might be associated with a reduction of wound infection [33] and healthcare costs [34].

Our study has some limitations. The retrospective nature of the study and the absence of a randomization might lead to allocation bias, and the small sample size to an underpowered statistical analysis. However, the two groups were similar in terms of age, sex and comorbidities. Furthermore, the use of strict inclusion criteria (i.e. the use of a single type of prosthesis) allowed us to reduce confounding variables.

\section{Conclusions}

The present study represents one of the few reports that analysed the reliability of the SP approach for the FNF in the elderly. This tissue-sparing approach seems to be effective in reducing the rate of transfusions. This data could positively affect a rapid functional recovery, thus reducing complications due to bed rest and health costs. Considering these results, the use of tissue-sparing approaches in patients with FNF under antithrombotic therapy may be desirable. However, a randomized controlled trial may be advisable to confirm our data.

Author contributions All authors contributed to the study conception and design. Material preparation, data collection and analysis were performed by ABC, GE and ADC. The first draft of the manuscript was written by $A B$ and $G T$, and all authors commented on previous versions of the manuscript. GB and ASP supervised the entire procedure. All authors read and approved the final manuscript. 
Funding Open access funding provided by Università degli Studi della Campania Luigi Vanvitelli within the CRUI-CARE Agreement. The authors did not receive support from any organization for the submitted work.

Availability of data and material Data and materials included in the present study are available upon reasonable request.

\section{Declarations}

Conflicts of interest The authors have no conflicts of interest to declare that are relevant to the content of this article.

Ethical approval According to Italian law, formal ethics approval was not required for this study, as it involved routine tests and clinical evaluations. The present study has been performed in accordance with the ethical standards as laid down in the 1964 Declaration of Helsinki and its later amendments or comparable ethical standards.

Informed consent All patients provided written and informed consent allowing to undergo surgery.

Consent for publication All patients provided written and informed consent to have their data collected for scientific and audit purposes.

Open Access This article is licensed under a Creative Commons Attribution 4.0 International License, which permits use, sharing, adaptation, distribution and reproduction in any medium or format, as long as you give appropriate credit to the original author(s) and the source, provide a link to the Creative Commons licence, and indicate if changes were made. The images or other third party material in this article are included in the article's Creative Commons licence, unless indicated otherwise in a credit line to the material. If material is not included in the article's Creative Commons licence and your intended use is not permitted by statutory regulation or exceeds the permitted use, you will need to obtain permission directly from the copyright holder. To view a copy of this licence, visit http://creativecommons.org/licenses/by/4.0/.

\section{References}

1. Lewis DP, Wæver D, Thorninger R, Donnelly WJ (2019) Hemiarthroplasty vs total hip arthroplasty for the management of displaced neck of femur fractures: a systematic review and meta-analysis. J Arthroplasty 34:1837-1843.e2. https://doi.org/ 10.1016/j.arth.2019.03.070

2. Suarez JC, Arguelles W, Saxena A et al (2020) Hemiarthroplasty vs total hip arthroplasty for femoral neck fractures: 2010-2017 trends in complication rates. J Arthroplasty. https://doi.org/10. 1016/j.arth.2020.02.040

3. Guyen O (2019) Hemiarthroplasty or total hip arthroplasty in recent femoral neck fractures? Orthop Traumatol Surg Res 105:S95-S101. https://doi.org/10.1016/j.otsr.2018.04.034

4. Grosso MJ, Danoff JR, Murtaugh TS et al (2017) Hemiarthroplasty for displaced femoral neck fractures in the elderly has a low conversion rate. J Arthroplasty 32:150-154. https://doi.org/ 10.1016/j.arth.2016.06.048

5. Wang X-D, Lan H, Hu Z-X et al (2020) SuperPATH minimally invasive approach to total hip arthroplasty of femoral neck fractures in the elderly: preliminary clinical results. Orthop Surg 12:74-85. https://doi.org/10.1111/os.12584
6. Barrett AA, Ezzibdeh RM, Horst PK et al (2019) Direct superior approach to the hip for total hip arthroplasty. JBJS Essent Surg Tech 9:e17. https://doi.org/10.2106/JBJS.ST.18.00078

7. Galakatos GR (2018) Direct anterior total hip arthroplasty. Mo Med 115:537-541

8. Jianbo J, Ying J, Xinxin L et al (2019) Hip hemiarthroplasty for senile femoral neck fractures: minimally invasive SuperPath approach versus traditional posterior approach. Injury 50:14521459. https://doi.org/10.1016/j.injury.2019.06.006

9. Arshi A, Lai WC, Iglesias BC et al (2020) Blood transfusion rates and predictors following geriatric hip fracture surgery. Hip Int J Clin Exp Res Hip Pathol Ther. https://doi.org/10.1177/ 1120700019897878

10. Transfusion Reactions - an overview / ScienceDirect Topics. https://www.sciencedirect.com/topics/biochemistry-geneticsand-molecular-biology/transfusion-reactions. Accessed on 25 Feb 2021

11. Rawn J (2008) The silent risks of blood transfusion. Curr Opin Anaesthesiol 21:664-668. https://doi.org/10.1097/ACO.0b013 e32830f $1 \mathrm{fd} 1$

12 Castillo B, Dasgupta A, Klein K et al (2018) Transfusion reactions. Transfusion Medicine for Pathologists. Elsevier

13. Tarantino U, Iolascon G, Cianferotti L et al (2017) Clinical guidelines for the prevention and treatment of osteoporosis: summary statements and recommendations from the Italian Society for Orthopaedics and Traumatology. J Orthop Traumatol 18:3-36. https://doi.org/10.1007/s10195-017-0474-7

14. Cooper C, Cole ZA, Holroyd CR et al (2011) Secular trends in the incidence of hip and other osteoporotic fractures. Osteoporos Int 22:1277-1288. https://doi.org/10.1007/s00198-011-1601-6

15. Guzon-Illescas O, Perez Fernandez E, Crespí Villarias N et al (2019) Mortality after osteoporotic hip fracture: incidence, trends, and associated factors. J Orthop Surg 14:203. https:// doi.org/10.1186/s13018-019-1226-6

16. Toro G, Lepore F, Cicala SD et al (2018) ABO system is not associated with proximal femoral fracture pattern in Southern Italy. Hip Int J Clin Exp Res Hip Pathol Ther 28:84-88. https:// doi.org/10.1177/1120700018813219

17. Ogawa T, Yoshii T, Moriwaki M et al (2020) Association between hemiarthroplasty vs total hip arthroplasty and major surgical complications among patients with femoral neck fracture. J Clin Med. https://doi.org/10.3390/jcm9103203

18. Jämsen E, Eskelinen A, Peltola M, Mäkelä K (2014) High early failure rate after cementless hip replacement in the octogenarian. Clin Orthop 472:2779-2789. https://doi.org/10.1007/ s11999-014-3641-7

19. Ogino D, Kawaji H, Konttinen L et al (2008) Total hip replacement in patients eighty years of age and older. J Bone Joint Surg Am 90:1884-1890. https://doi.org/10.2106/JBJS.G.00147

20. De Cicco A, Toro G, Oliva F et al (2021) Atypical periprosthetic femoral fractures of the hip: a PRISMA compliant systematic review. Injury. https://doi.org/10.1016/j.injury.2021.03.042

21. Toro G, Bothorel H, Saffarini M et al (2019) Uncemented total hip arthroplasty in octogenarian and nonagenarian patients. Eur J Orthop Surg Traumatol Orthop Traumatol 29:103-110. https:// doi.org/10.1007/s00590-018-2242-7

22. Leunig M, Hutmacher JE, Ricciardi BF et al (2018) Skin crease 'bikini' incision for the direct anterior approach in total hip arthroplasty. Bone Jt J. https://doi.org/10.1302/0301-620X. 100B7.BJJ-2017-1200.R2

23. Neyisci C, Erdem Y, Bilekli AB, Bek D (2020) Direct anterior approach versus posterolateral approach for hemiarthroplasty in the treatment of displaced femoral neck fractures in geriatric patients. Med Sci Monit Int Med J Exp Clin Res. https://doi.org/ 10.12659/MSM.919993 
24. Xu K, Anwaier D, He R et al (2019) Hidden blood loss after hip hemiarthroplasty using the superPATH approach: a retrospective study. Injury 50:2282-2286. https://doi.org/10.1016/j. injury.2019.10.013

25. Bodrogi AW, Sciortino R, Fitch DA, Gofton W (2016) Use of the supercapsular percutaneously assisted total hip approach for femoral neck fractures: surgical technique and case series. J Orthop Surg 11:113. https://doi.org/10.1186/ s13018-016-0446-2

26. Daugaard C, Pedersen AB, Kristensen NR, Johnsen SP (2019) Preoperative antithrombotic therapy and risk of blood transfusion and mortality following hip fracture surgery: a Danish nationwide cohort study. Osteoporos Int J Establ Result Coop Eur Found Osteoporos Natl Osteoporos Found USA 30:583-591. https://doi. org/10.1007/s00198-018-4786-0

27. Wang J-Q, Chen L-Y, Jiang B-J, Zhao Y-M (2020) Development of a nomogram for predicting blood transfusion risk after hemiarthroplasty for femoral neck fractures in elderly patients. Med Sci Monit Int Med J Exp Clin Res. https://doi.org/10.12659/MSM. 920255

28. Madjdpour C, Heindl V, Spahn DR (2006) Risks, benefits, alternatives and indications of allogenic blood transfusions. Minerva Anestesiol 72:283-298

29. Forbes JM, Anderson MD, Anderson GF et al (1991) Blood transfusion costs: a multicenter study. Transfusion (Paris) 31:318-323. https://doi.org/10.1046/j.1537-2995.1991.31491213295.x
30. Cantor SB, Hudson DV, Lichtiger B, Rubenstein EB (1998) Costs of blood transfusion: a process-flow analysis. J Clin Oncol Off $\mathbf{J}$ Am Soc Clin Oncol 16:2364-2370. https://doi.org/10.1200/JCO. 1998.16.7.2364

31. Crémieux PY, Barrett B, Anderson K, Slavin MB (2000) Cost of outpatient blood transfusion in cancer patients. J Clin Oncol Off J Am Soc Clin Oncol 18:2755-2761. https://doi.org/10.1200/JCO. 2000.18.14.2755

32. Abraham I, Sun D (2012) The cost of blood transfusion in Western Europe as estimated from six studies. Transfusion (Paris) 52:1983-1988. https://doi.org/10.1111/j.1537-2995.2011.03532.x

33. Taneja A, El-Bakoury A, Khong H et al (2019) Association between allogeneic blood transfusion and wound infection after total hip or knee arthroplasty: a retrospective case-control study. J Bone Jt Infect 4:99-105. https://doi.org/10.7150/jbji.30636

34. Ristagno G, Beluffi S, Menasce G et al (2018) Incidence and cost of perioperative red blood cell transfusion for elective spine fusion in a high-volume center for spine surgery. BMC Anesthesiol 18:121. https://doi.org/10.1186/s12871-018-0591-8

Publisher's Note Springer Nature remains neutral with regard to jurisdictional claims in published maps and institutional affiliations. 